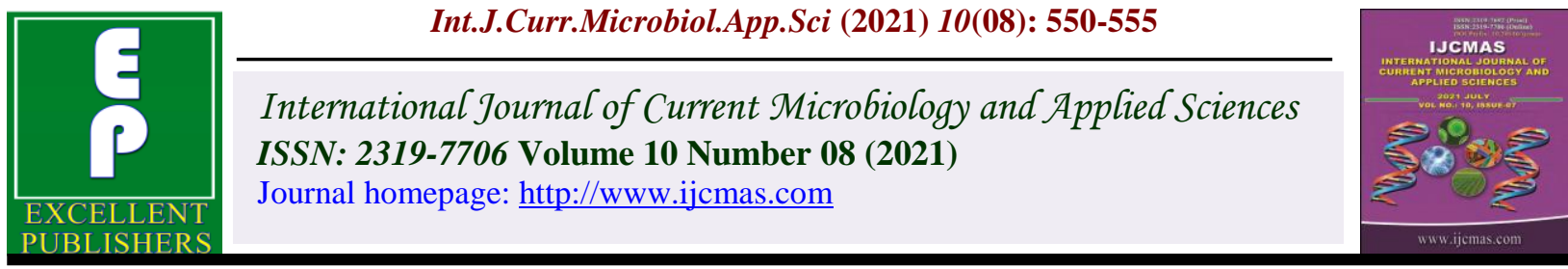

\title{
Diagnosis and Therapeutic Management of Hepatozoonosis in Dog
}

\author{
M. Mondal*, A. Maity, D. Mandal, P. S. Jana, M. Roy, M. C. Pakhira, \\ F. Mridha, A. Soren, R. Raj and K. Kumar \\ Faculty of Veterinary and Animal Sciences, West Bengal University of Animal and Fishery \\ Sciences, Kolkata-700037, India \\ *Corresponding author
}

A B S T R A C T

Keywords

Hepatozoon canis, haematology, biochemical alteration, therapeutic management Article Info

\section{Accepted:}

20 July 2021

Available Online:

10 August 2021
The present communication depicts the detection and therapeutic management of canine hepatozoonosis. A total ten dogs of different breeds having symptoms of varying degrees of fever, emesis, anorexia etc were presented to the Department of Veterinary Clinical Complex at West Bengal University of Animal and Fishery Sciences, Kolkata 700037, India during the period from May-December 2020. Most of the infected dogs showed pale conjunctival and oral mucus membrane, peripheral lymphadenopathy and hepatomegaly. Blood was collected for hematology, serum was harvested for biochemical estimation and Giemsa stained blood smear was made for diagnosis of Hepatozoon canis from naturally infected dogs. Haematological and serum biochemical findings revealed hypohaemoglobinaemia and erythrocytopaenia and lowered PCV clearly indicating anemia, lymphocytosis, hyperbilirubinemia, hypoalbuminemia, hyperglobulinemia and increased transaminase activities accompanied by elevated level of Alkaline Phosphatase. These cases were diagnosed as hepatozoonosis since examination of blood smear revealed presence of Hepatozoon canis gamonts inside neutrophils. The affected dogs were treated with a combination therapy including single dose of Inj. Imidocarb dipropionate $(6.6 \mathrm{mg} / \mathrm{kg}$ subcutaneously) and orally Tab. Doxycycline $(5 \mathrm{mg} / \mathrm{kg})$ twice daily for 28 days. Supportive therapy was given with antiemetics, hematinics and plasma expanders. Majority of the affected dogs depicted uneventful recovery after 28 days of therapeutic management.

\section{Introduction}

James (1905) first reported canine hepatozoonosis from India. Two Hepatozoon species has been recognized namely: Hepatozoon canis and Hepatozoon americanum. Hepatozoon species affects mostly mammalian leukocytes and is an epicomplexan parasite of family Hepatozoidae (Baneth et al., 2001). It develops asexually with merogony followed by gamontogony in a vertebrate intermediate (dog) and sexual development culminating to sporogony in a hematophagous invertebrate definitive host i.e. 
tick (Smith, 1996). Disease transmission occurs by ingestion of Rhipicephalus sanguineus tick belonging to family Ixodidae. But mixed infections are possible with hepatozoonosis as single tick may harbor multiple pathogens (Banerjee et al., 2008).

Subclinical infection may remain unnoticed unless concurrent infection with other pathogens is present (Otranto et al., 2011). Hepatozoon canis gamonts are usually observed in neutrophils and macrophages (Rubini et al., 2008). The present communication represents the effect of combination therapy of imidocarb dipropionate and doxycycline against Hepatozoon canis infection.

\section{Materials and Methods}

A total ten dogs of different breeds having symptoms of varying degrees of fever, emesis, anorexia etc were presented to the clinics at West Bengal University of Animal and Fishery Sciences, Belgachia, Kolkata 700037, India during the period from May-December 2020. Routine deworming and vaccination were done as per schedule in vogue.

Most of them showed pale conjunctival and oral mucus membrane, peripheral lymphadenopathy and hepatomegaly. Blood and serum samples were collected for haematology and serum biochemistry, respectively and the peripheral blood smears were prepared and stained with Giemsa stain after methanol fixation (Sathpathi et al., 2014; Mondal, 2019). The stained blood smears were screened for haemoprotozoa under light microscope. Haematological analysis was carried out as per standard method (Jain, 1986) and biochemical analysis was done with semi-autoanalyzer. The haemato-biochemical values were compared with normal reference values and interpreted accordingly.

\section{Results and Discussion}

Results on haemato-biochemical examination were summarized in table. Haematological alterations revealed hypohaemoglobinaemia and erythrocytopaenia and lowered PCV clearly indicating anemia $(\mathrm{Hb}: 8.25 \pm 0.26 \mathrm{~g} / \mathrm{dl}$, RBC: $3.8 \pm 0.1$ million $/ \mathrm{mm}^{3}$ and PCV: $26.7 \pm 0.6 \%)$ and lymphocytosis $(28.7 \pm 1.05 \%)$. Biochemical examination showed hyperbilirubinemia $\quad(0.38 \pm 0.03 \mathrm{mg} / \mathrm{dl})$, hypoalbuminemia $\quad(2.27 \pm 0.02 \quad \mathrm{~g} / \mathrm{dl})$, hyperglobulinemia $(4.54 \pm 0.13 \mathrm{~g} / \mathrm{dl})$ and increased transaminase activities (ALT:

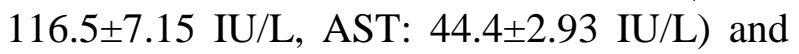
elevated level of Alkaline Phosphatase $(160.8 \pm 3.06 \mathrm{IU} / \mathrm{L})$. The stained peripheral blood smears of all affected dogs were positive for Hepatozoon canis gamont in neutrophils (Fig). Based on history, clinical manifestation and laboratory findings comprised of microscopical examination and haemato-biochemical alterations, these cases were diagnosed as Hepatozoon canis infections.

The treatment was started with combination therapy including single dose of Inj. Imidocarb dipropionate @ $6.6 \mathrm{mg} / \mathrm{kg}$, subcutaneously and Tab. Doxyxycline @ 5 $\mathrm{mg} / \mathrm{kg}$, orally twice daily for 28 days. Fiprofort Plus TM (Fipronil + S-methoprene) spot on was applied topically for tick management. Supportive therapy was done with Inj. NS @ $250 \mathrm{ml}$ intravenously, Inj. Haemaccel TM ( $5 \mathrm{ml} / \mathrm{kg}$ intravenously), Inj. Meloxicam @0.5 mg/kg, intramuscularly twice daily, Inj. Pantoprazole @1 mg/kg intravenously, Inj. Ondansetron @ $0.2 \mathrm{mg} / \mathrm{kg}$ intravenously twice daily for 3 days. 
Table.1 Haemato-biochemical alterations of domestic dogs naturally suffering from hepatozoonosis (Mean \pm SE of ten replicates)

\begin{tabular}{|c|c|c|}
\hline Parameters & Values & References \\
\hline $\mathrm{Hb}(\mathrm{g} / \mathrm{dl})$ & $8.25 \pm 0.26$ & $12-19$ \\
\hline RBC (million/mm³) & $3.8 \pm 0.1$ & $5.0-7.9$ \\
\hline WBC $\left(10^{3}\right.$ cells $\left./ \mathrm{mm}^{3}\right)$ & $12.8 \pm 0.31$ & $5.0-14.1$ \\
\hline \multicolumn{3}{|l|}{ Differential count } \\
\hline Neutrophil (\%) & $67.9 \pm 0.95$ & $58-85$ \\
\hline Lymphocyte (\%) & $28.7 \pm 1.05$ & $8-21$ \\
\hline Monocyte (\%) & $2.2 \pm 0.33$ & $2-10$ \\
\hline Eosinophil (\%) & $2.1 \pm 0.23$ & $0-9$ \\
\hline Basophil (\%) & 00 & $0-1$ \\
\hline PCV $(\%)$ & $26.7 \pm 0.6$ & $35-57$ \\
\hline Platelet count (lakhs $/ \mathrm{mm}^{3}$ ) & $2.27 \pm 0.07$ & $2.11-6.21$ \\
\hline Urea $(\mathrm{mg} / \mathrm{dl})$ & $31.2 \pm 1.14$ & $17-60$ \\
\hline BUN (mg/dl) & $16.5 \pm 0.48$ & $8-28$ \\
\hline Creatinine (mg/dl) & $1.05 \pm 0.07$ & $0.5-1.7$ \\
\hline $\mathrm{Na}(\mathrm{nmol} / \mathrm{l})$ & $146 \pm 0.61$ & $142-152$ \\
\hline K (nmol/l) & $4.15 \pm 0.02$ & $3.9-5.1$ \\
\hline Total Bilirubin (mg/dl) & $0.38 \pm 0.03$ & $0-0.3$ \\
\hline Direct Bilirubin (mg/dl) & $0.18 \pm 0.01$ & $0-0.2$ \\
\hline Indirect Bilirubin (mg/dl) & $0.21 \pm 0.03$ & $0-0.1$ \\
\hline Total Protein (g/dl) & $6.81 \pm 0.13$ & $5.4-7.5$ \\
\hline Albumin (g/dl) & $2.27 \pm 0.02$ & $2.3-3.1$ \\
\hline Globulin (g/dl) & $4.54 \pm 0.13$ & $2.4-4.4$ \\
\hline ALT (IU/L) & $116.5 \pm 7.15$ & 10-109 \\
\hline AST $($ IU/L) & $44.4 \pm 2.93$ & $13-15$ \\
\hline Alkaline Phosphatase (IU/L) & $160.8 \pm 3.06$ & $1-114$ \\
\hline
\end{tabular}

Fig.1 Hepatozoon canis gamont in neutrophils (Giemsa stain, $1000 \mathrm{X}$ ) 

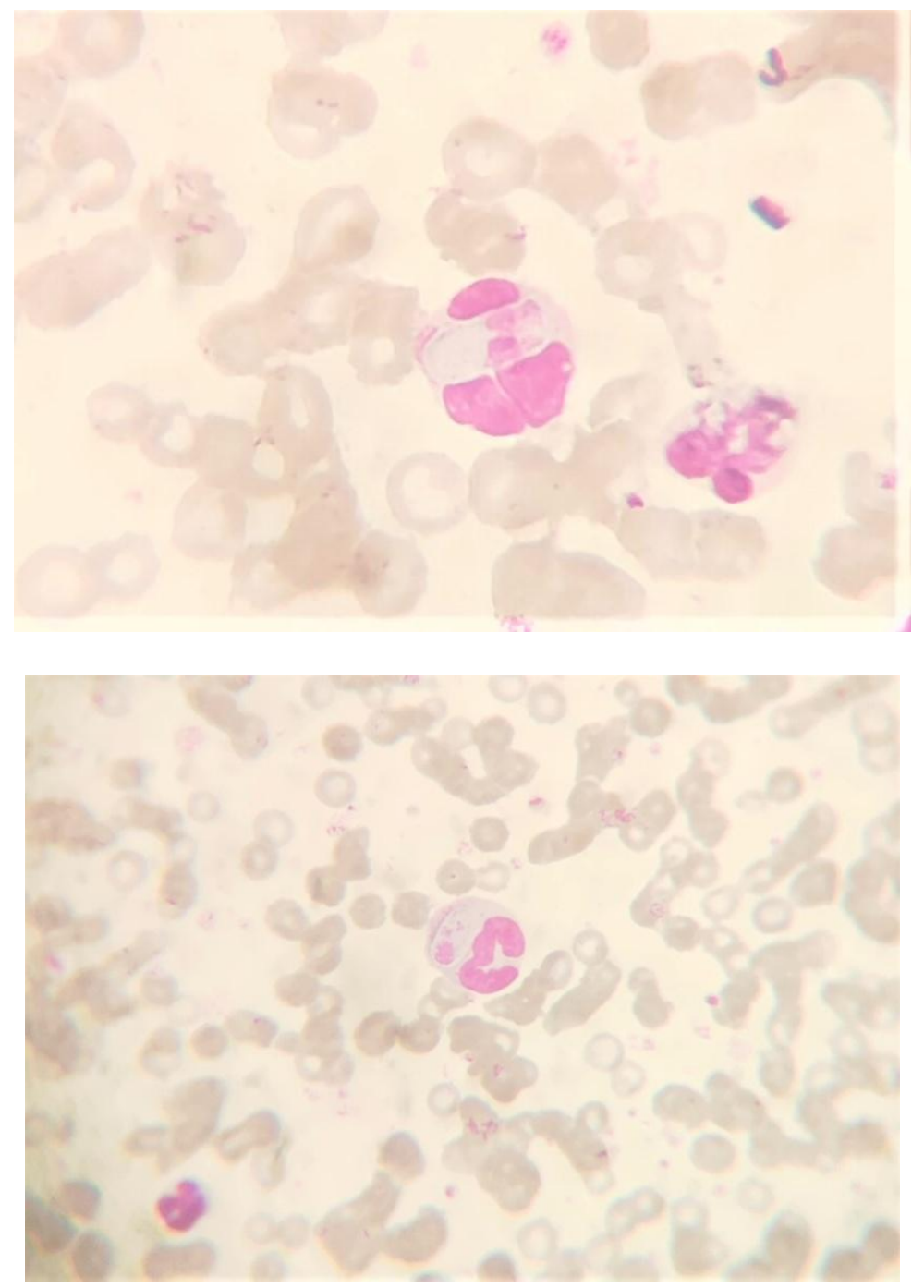

Along with this, hematinic (Syrup Dexorange TM @ $10 \mathrm{ml}$ orally twice daily) and hepatoprotectant (Syrup Sylibon TM $10 \mathrm{ml}$ orally twice daily) were given for 4 weeks. After 4 weeks of therapy, majority of the ailing dogs showed marked improvement in condition and recovered.

Canine hepatozoonosis caused by Hepatozoon canis is an important canine haemoprotozoan disease occurring globally (Rajamanickam et al., 1985; Ewing and Panciera et al., 2003). Clinical manifestations like fever, emesis, anorexia were simulating with the earlier reports of (Baneth, 2006; Paşa et al., 2009; Thakur et al., 2018). Haemato-biochemical alterations like marked anaemia, lymphocytosis, hyperbilirubinemia, hypoalbuminemia, hyperglobulinemia and elevated levels of liver specific aminotranferase activities were in conformity with earlier findings (Sarma et al., 2012; Thakur et al., 2018). Anemia in hepatozoonosis might be due to huge tick infestation or bone marrow suppression (Baneth, 2006; Marchetti et al., 2009; Thakur et al., 2018). In the present study, hypoalbuminemia and hyperglobulinemia have been recorded in canine hepatozoonosis, as site of albumin synthesis is liver, which is mostly affected in hepatozoonosis (Paşa et al., 2009; Pawar and Gatne, 2005). Doxycycline is 
the drug of choice for treatment of hepatozoonosis in canines (Kumar et al., 2012). It has concluded that the combination therapy of imidocarb dipropionate and doxycycline along with supportive therapy (fluids, antiemetics, hematinic and hepatoprotectives) might be a successful choice for proper management of hepatozoonosis induced acute hepatitis in canine.

\section{References}

Banerjee, P. S., Mylonakis, M. E., Garg, R., Vatysa, S. and Yadav, C. L. (2008). Concurrent hepatozoonosis, monocytic and granulocytic ehrlichiosis in a dog. Journal of Veterinary Parasitology, 22: 9-11.

Baneth, G. (2006). Hepatozoonosis. In: Greene CE (Ed) Infectious diseases of the dog and cat, 3rd edn. W.B. Saunders, Philadelphia, 698-705.

Baneth, G. A. D., Samish, M., Alekseev, E., Aroch, I. and Shkap, V. (2001). Transmission of Hepatozoon canis to dogs by naturally-fed or percutaneously-injected Rhipicephalus sanguineus ticks. Journal of Parasitology, 87(3): 606-611.

Ewing, S. A. and Panciera, R. J. (2003). American canine hepatozoonosis. Clinical Microbiology Reviews, 16(4): 688-697.

Jain, N. C. (1986). Schalm's Veterinary Hematology. Fourth ed., Lea and Febiger, Philadelphia.

James, S.P. (1905). On a parasite found in white corpuscles of the blood of dogs. In: Scientific memoirs by the office of the medical and sanitary departments of the government of India. Office of Govt Print, India, 14:1-12.

Kumar, T., Niddhi, A., and Rajora, V. S. (2012). Hepatozoonosis and its therapeutic management in a dog. Intas Polivet, 13(1): 138-139.
Marchetti, V., Lubas, G., Baneth, G., Modenato, M. and Mancianti, F. (2009). Hepatozoonosis in a dog with skeletal involvement and meningoencephalomyelitis. Veterinary Clinical Pathology, 38(1): 121-125.

Mondal, M. (2019). Veterinary Laboratory Diagnosis. $\quad 1^{\text {st }}$ Edn, Narendra Publishing House, Delhi, India.

Otranto, D., Dantas-Torres, F., Weigl, S., Latrofa, M. S., Stanneck, D. and de Caprariis, D. (2011). Diagnosis of Hepatozoon canis in young dogs by cytology and PCR. Parasites \& Vectors, 4: 55.

Paşa, S., Kiral, F., Karagenc, T., Atasoy, A. and Seyrek, K. (2009). Description of dogs naturally infected with Hepatozoon canis in the Aegean region of Turkey. Turkish Journal of Veterinary and Animal Sciences, 33(4): 289-295.

Pawar, S. D. and Gatne, M. L. (2005). Some haematological and biochemical profiles in canine hepatozoonosis. Journal of Veterinary Parasitology, 19(2): 171-172.

Rajamanickam, C., Weisenhutter, E., Zin, F. M. D. and Hamid, J. (1985). The incidence of canine hematozoa in peninsular Malaysia. Veterinary Parasitology, 17:151-157.

Rubini, A. S., dos Santos Paduan, K., Lopes, V. V. A. and O'Dwyer, L. H. (2008). Molecular and parasitological survey of Hepatozoon canis (Apicomplexa: Hepatozoidae) in dogs from rural area of Sao Paulo state, Brazil. Parasitology Research, 102(5): 895.

Sarma, K., Mondal, D. B., Saravanan, M., Kumar, M. and Mahendran, K. (2012). Haemato-biochemical changes in Hepatozoon canis infected dog before and after therapeutic management. Journal of Veterinary Parasitology, 26(1): 35-38. 
Sathpathi, S., Mohanty, A. K., Satpathi, P., Mishra, S. K., Behera, P. K. and Patel, G. (2014). Comparing Leishman and Giemsa staining for the assessment of peripheral blood smear preparations in a malaria-endemic region in India. Malaria Journal, 13(1): 512.

Smith, T. G. (1996). The genus Hepatozoon (Apicomplexa: Adeleina). Journal of Parasitology, 565-585.
Thakur, N., Chethan, G. E., Akhilesh, Lekshman, A., Kumari, P., Shehzad, M., Rajesh, J. B., Mahendran, K., De, U. K. and Banerjee, P. S. (2018). Therapeutic management of Hepatozoon canis induced acute hepatitis in a dog Journal of Entomology and Zoology Studies, 6(4): 1037-1039.

\section{How to cite this article:}

Mondal, M., A. Maity, D. Mandal, P. S. Jana, M. Roy, M. C. Pakhira, F. Mridha, A. Soren, R. Raj and Kumar, K. 2021. Diagnosis and Therapeutic Management of Hepatozoonosis in Dog. Int.J.Curr.Microbiol.App.Sci. 10(08): 550-555. doi: https://doi.org/10.20546/ijcmas.2021.1008.065 